\section{One-lung or two-lung ventilation during transthoracic oesophagectomy?}

Mitsuo Tachibana MD, Shunichi Abe MD, Hideki Tabara MD, Hiroshi Yoshimura MD, Hiroshi Matsuura MD, Naofumi Nagasue MD, Teruhisa Nakamura MD
The purpose of this study was to determine the safety of onelung ventilation (OLV) during transthoracic oesophagectomy. Changes in circulatory and respiratory variables during and after operation were compared in patients receiving $O L V$ or conventional two-lung ventilation (TLV). Thirty patients undergoing transthoracic oesophagectomy were randomly divided into either the OLV or the TLV group. During thoracotomy, $\mathrm{FlO}_{2}$ was kept to 1.0. The $\mathrm{PaO}_{2}$ in the OLV group decreased from the prethoracotomy value of $467 \pm 84 \mathrm{~mm} \mathrm{Hg}$ to 227 $\pm 162 \mathrm{mmHg}$ during OLV. This decrease was greater than the decrease from $484 \pm 79 \mathrm{~mm} \mathrm{Hg}$ to $380 \pm 119 \mathrm{~mm} \mathrm{Hg}$ in the $T L V$ group $(P<0.05)$. The shunt ratio increased in the OLV group from $20 \pm 7 \%$ to $35 \pm 13 \%$ during OLV which was greater than the increase in the TLV group (26 $\pm 7 \%$ from $17 \pm 8 \%)(P<0.05)$. Other variables and the incidence of the complications, however, were little different between the two groups during and afier OLV and up to POD 3. It is concluded that $O L V$ is as safe as TLV during oesophagectomy.

Cette étude vise à évaluer la sécurité de la ventilation unipulmonaire (OLV) pendant l'oesophagectomie transthoracique. Les modifications aux variables circulatoires et respiratoire pendant et après lintervention sont comparées chez des patients en OLV ou sous ventilation conventionnelle bipulmonaire (TLV). Trente patients subissant une oesophagectomie transthoracique sont répartis au hasard entre les groupes OLV et TLV. Pendant la thoracotomie, la $\mathrm{FIO}_{2}$ est maintenue $\dot{a} \cdot 1,0$. Dans le groupe OLV, la $\mathrm{PaO}_{2}$ baisse pendant l'OLV de la valeur préthoracotomie de $467 \pm 84 \mathrm{mmHg}$ à $227 \pm 162 \mathrm{~mm} \mathrm{Hg}$. Cette baisse est plus importante que la baisse de $484 \pm 79 \mathrm{~mm} \mathrm{Hg}$ à 380

\section{Key words}

ANAESTHESIA: thoracic;

EQUIPMENT: tubes, endobronchial.

From the Second Department of Surgery, Shimane Medical University, Izumo 693, Japan.

Address correspondence to: Dr. Mitsuo Tachibana, Second Department of Surgery, Shimane Medical University, Izumo 693, Japan.

Accepted for publication 30th April, 1994. $\pm 119 \mathrm{mmHg}$ qui survient dans le groupe TLV $(P<0,05)$. La fraction de shunt augmente dans le groupe OLV de 20 $\pm 7 \%$ à $35 \pm 13 \%$ pendant l'OLV, ce qui constitue une augmentation plus importante que l'augmentation constatée dans le groupe TLV (de $17 \pm 8 \%$ à $26 \pm 7 \%)(P<0,05)$. Cependant, les autres variables et lincidence des complications ne different pas entre les deux groupes pendant et après OLV jusqu'au troisième jour postopératoire. Pendant l'oesophagectomie, la marge de sécurité est la même entre OLV et TLV.

One-lung ventilation (OLV) during thoracotomy for oesophagectomy was first reported by Scherer, ' followed by several authors. ${ }^{2-4}$ The purpose is to achieve good surgical exposure and to allow aggressive lymphadenectomy around the upper mediastinum. It is not known whether the collapsed lung during OLV affects cardiopulmonary variables and postoperative pulmonary complications or whether compression of the lung and heart to achieve good surgical conditions during conventional two-lung ventilation (TLV) affect cardiopulmonary function. Therefore, we evaluated the safety of OLV compared with TLV, examining the circulatory and respiratory changes during and after transthoracic oesophagectomy.

\section{Methods}

Thirty patients with carcinoma of the thoracic oesophagus were prospectively randomized into two groups to receive either left OLV or conventional TLV group during transthoracic oesophagectomy. All tracheas were intubated with a Carlens' endobronchial double lumen tube. ${ }^{5}$ In 15 patients, the lungs were ventilated by left OLV immediately after opening the chest whilst in the other 15 , TLV was maintained. Hexothane $(<1.0 \%$ inspired) and neuroleptanalgesia with epidural anaesthesia were used during thoracotomy. The lungs were ventilated as follows: $\mathrm{FrO}_{2} 1.0$, tidal volume $10 \mathrm{ml} \cdot \mathrm{kg}^{-1}$, and average respiratory rate of $16 \mathrm{bpm}$, adjusted to maintain $\mathrm{PaCO}_{2}$ of 35-45 mmHg. In the TLV group, hyperinflation was freely applied. Before closing the chest, the lungs were expanded to a maximum inspiratory pressure of $30 \mathrm{~cm}$ $\mathrm{H}_{2} \mathrm{O}$ in both groups. 


\section{Teasurements and calculations}

- 7F Swan-Ganz catheter (American Edwards LaboItories, Irvine, Calif.) was inserted into the pulmonary rtery via the right external jugular vein at the beginning $f$ anaesthesia. A left radial artery was cannulated with $23 \mathrm{G}$ cannula tube for determination of mean arterial lood pressure (mBP) and blood gas analysis using acidase analyzer (Radiometer, ABL30). These catheters were snnected to a pressure transducer (Nihon Kohden, TP$0 \mathrm{~T}$ ) and the pressure wave form was displayed on the uulti-chart recorder (Nihon Kohden, RM-6000).

Measured variables included heart rate (HR), central znous pressure (CVP), $\mathrm{mBP}$, mean pulmonary arterial ressure (mPAP), and pulmonary capillary wedge presire (PCWP).

The arterial catheter was used to sample blood for lood gas analysis. The pulmonary artery catheter alwed sampling of mixed venous blood gas for analysis i well as measurement of cardiac output (CO) by tripsate thermal dilution using a cardiac output computer American Edward, 9520).

From these primary measurements, the following physlogical secondary variables were derived using standard rrmulas: cardiac index (CI), stroke volume index (SVI), istemic vascular resistance (SVR), pulmonary vascular sistance (PVR), left ventricular stroke work index VSWI), right ventricular stroke work index (RVSWI).

The alveolar oxygen tension was estimated by applying ie standard alveolar air equation and the oxygen connts of arterial, mixed venous, and capillary blood were alculated using the following formula: ${ }^{6}$

$\mathrm{O}_{2}=1.34 \times \mathrm{Hb} \times \mathrm{SO}_{2}+0.0031 \times \mathrm{PO}_{2}$

hen, physiological shunt was calculated.

After 15 min under stable condition, baseline measrements were obtained as control (preoperative) and rezated at 15, 30, 60, 90 min after the chest was open ntraoperative), and at the first, second, and third postperative days (POD).

\section{hest $x$-ray}

hest $x$-ray appearances of the two groups were examed on POD 1, 2, 3, 5, 7, 10, 14, 20, 30. Abnormal spearances were classified into four types: (1) a patchy ittern with scattered small nodules and reticular shadow : less than $10 \mathrm{~mm},(2)$ an infiltrative pattern with clearly :fined nodules more than $10 \mathrm{~mm}$ in size, (3) a widely sseminated pattern like atelectasis, and (4) a vascular ittern with high density hilar vascular shadows. The lottion of these shadows was divided into four regions: lateral upper and lower regions with referring the height : the right interlobar fissure (hairline). The duration and cation of abnormal shadows were investigated.
TABLE I Patient characteristics

\begin{tabular}{lcl}
\hline & $T L V(n=15)$ & $O L V(n=15)$ \\
\hline Age (yr) & $62.1 \pm 8.8$ & $64.0 \pm 5.1$ \\
Sex (M/F) & $14 / 1$ & $14 / 1$ \\
$\begin{array}{l}\text { Tumour location } \\
\text { - Upper/Middle/Lower }\end{array}$ & $2 / 7 / 6$ & $3 / 9 / 3$ \\
stage $^{7}$ & & \\
- - $/ \mathrm{I} / \mathrm{II} / \mathrm{II} / \mathrm{IV}$ & $2 / 0 / 1 / 2 / 10$ & $4 / 0 / 1 / 3 / 7$ \\
curability & & \\
- III/II/I/0 & $5 / 0 / 4 / 6$ & $7 / 0 / 3 / 5$ \\
Spirometry & & \\
- VC (ml) & $3810 \pm 882$ & $3552 \pm 660$ \\
- \%VC & $115 \pm 21$ & $111 \pm 14$ \\
- \%FEV & $74.5 \pm 6.4$ & $71.1 \pm 11.6$ \\
Op. time (min) & $387 \pm 60$ & $408 \pm 43$ \\
Blood loss (ml) & $1068 \pm 705$ & $976 \pm 460$ \\
Duration of open chest (min) & $139 \pm 28$ & $137 \pm 27$ \\
Duration of OLV (min) & - & $101 \pm 17$ \\
\hline
\end{tabular}

Mean \pm SD. $P$. NS.

\section{Postoperative complications}

Pulmonary complications were defined by the following criteria: abnormal shadow on the chest $x$-ray as pneumonia, atelectasis, and oedema, hypoxia $\left(\mathrm{PaO}_{2}<100\right.$ mmHg with $\mathrm{FIO}_{2} 0.4$ over $12 \mathrm{hr}$ ), and/or prolonged ventilation for $>$ five days. Moderate pneumothorax and pleural effusion were excluded.

\section{Analytic method}

Results are expressed as mean (M) $\pm \mathrm{SD}$. The ANOVA test was used to test for significant level of differences among groups and Chi-square test for patient characteristics and rates of postoperative complications. Probability values of $P<0.05$ were considered to be statistically significant.

\section{Results}

Characteristics of the 30 patients are shown in Table I. Mean age, sex ratio, tumour location, stage, assessment of curability, ${ }^{7}$ and preoperative spirometry of both groups were not different. Blood loss during operation, $1068 \pm$ $705 \mathrm{ml}$ in the TLV group, was not different from that, $976 \pm 460 \mathrm{ml}$, in the OLV group. The duration of open chest was $139 \pm 28 \mathrm{~min}$ in the TLV group and $137 \pm$ $29 \mathrm{~min}$ in the OLV group and the duration of OLV was $101 \pm 17 \mathrm{~min}$ (range 70-120 $\mathrm{min}$ ).

In 29 patients the oesophagus was substituted with the greater curvature of the stomach retrosternally and in one (TLV group) with the right hemi-colon in the antethoracic route.

In one patient OLV was unsatisfactory because of an inconvenient position of endotracheal tube. Reintubation with a conventional single-lumen nasotracheal tube required $18 \pm 6 \mathrm{~min}$. 
TABLE II Postoperative complications

\begin{tabular}{lll}
\hline & $T L V$ & OLV \\
\hline Pulmonary & $5(33.3 \%)$ & $4(26.7 \%)$ \\
- Pneumonia & 2 (aspiration) & 1 \\
- Pulmonary oedema & & 1 \\
- Atelectasis & 1 & \\
- Bronchial erosion & 1 & 2 \\
- Pyothorax & 1 & $2(13.3 \%)$ \\
Anastomotic leak & $1(6.7 \%)$ & $2(13.3 \%)$ \\
Intraabdominal abscess & & \\
DIC & $1(6.7 \%)$ & \\
\hline
\end{tabular}

DIC: disseminated intravascular coagulopathy. $P$. NS.

\section{Postoperative complications}

Five patients (33.3\%) in the TLV group and four (26.7\%) in the OLV group developed pulmonary complications. In the TLV group, two had aspiration pneumonia due to recurrent nerve paralysis on POD 13 and 18, one developed atelectasis due to sputum retention on POD 2, one had bronchial erosion on PDO 4 due to aggressive lymphadenectomy and one had a pyothorax. In the OLV group one patient developed pneumonia associated with mediastinitis from cervical anastomotic leakage on POD 5 , one had pulmonary oedema due to cardiac failure on POD 3, and two developed pyothorax. Other nonpulmonary complications consisted of one anastomotic leakage in the TLV group and two in the OLV group, two intraabdominal abscess in the OLV group, and one disseminated intravascular coagulation (DIC) in the TLV group (Table II).

\section{Circulatory variables}

Circulatory changes are shown in Table III. There was no difference between the OLV and TLV groups up to POD 3. Compared with preoperative values the HR increased on POD 2 and POD 3 in both groups $(P<$ 0.05 ), and CVP and SVR in the OLV group decreased after surgery $(P<0.05)$.

\section{Respiratory variables}

Respiratory changes are shown in Table IV. The $\mathrm{PaO}_{2}$ in the OLV group decreased from the prethoracotomy value of $467 \pm 84 \mathrm{mmHg}$ to $227 \pm 162 \mathrm{mmHg}$ during OLV and this decrease was greater than the decrease to $380 \pm 119 \mathrm{mmHg}$ from $484 \pm 79 \mathrm{mmHg}$ in the TLV group $(P<0.05)$. The decrease of $\mathrm{PaO}_{2}$ continued during $90 \mathrm{~min}$ by $\mathrm{OLV}$. However, $\mathrm{PaO}_{2}$ returned to prethoracotomy values after OLV was stopped. No difference was found between the two groups in the postoperative period (Figure 1). In the OLV group, seven patients (46.7\%) had $\mathrm{PaO}_{2}<100 \mathrm{mmHg}$ and in one hyperinflation was applied at 30 and $60 \mathrm{~min}$ after the beginning of OLV be- cause of $\mathrm{PaO}_{2}$ of $63.7 \mathrm{mmHg}$. The $\dot{\mathrm{Q}} \mathrm{s} / \mathrm{Q} t$ increased in the OLV group from $20 \pm 7 \%$ to $35 \pm 13 \%$ during OLV which was greater than the increase in the TLV group (26 $\pm 7 \%$ from $17 \pm 8 \%)(P<0.05)$. However, the Qs/Qt returned to prethoracotomy value in the postoperative period and no difference was found between both groups (Figure 2). The $\mathrm{A}-\mathrm{aDO}_{2}$ and the $\mathrm{RI}$ increased more during OLV than TLV $(P<0.05)$. The $\mathrm{A}-\mathrm{aDO}_{2}$ decreased after surgery in both groups. In summary, in the OLV group $\mathrm{PaO}_{2}, \mathrm{Q} \mathrm{s} / \mathrm{Qt}, \mathrm{A}-\mathrm{aDO}_{2}$, and $\mathrm{RI}$ changed transiently during OLV but returned to prethoracotomy values after closing the chest.

\section{Chest $x$-ray}

Abnormal shadows were seen in $40 \%$ of patients on POD 2 and POD 3 in the TLV gorup and in 33\% from POD 3 to POD 10 in the OLV group (P. NS) (Figure 3). Of the 25 lesions in the TLV group eleven were patchy (44\%), eight had a vascular pattern (32\%), four infiltration $(16 \%)$ and two had a disseminated pattern (8\%). In 19 lesions of the OLV group, seven were patchy with infiltration (36.8\%), four vascular (21.1\%) and one had a disseminated pattern (5.3\%). Abnormal shadows were located in the right lower region in $66.7 \%$ on POD 2 and POD 3 in the TLV group and $60.0 \%$ on POD 5 and POD 7 in the OLV group. Shadows occurred in left lower region in $22.2 \%$ of TLV and $16.7 \%$ of OLV. Lesions were infrequent in bilateral upper regions. The patchy and vascular abnormal shadows were obvious between POD 2 and POD 7 in the right lower region in both groups.

\section{Discussion}

The indications for one-lung ventilation (OLV) can be divided into absolute and relative indications. ${ }^{8}$ In the latter, OLV during oesophageal resection is to obtain a better surgical exposure but has a low priority. On the other hand, Scherer' reported OLV in oesophageal surgery in 1984 , which was followed by several other reports. ${ }^{2-4,9}$ The purpose of OLV is to achieve good surgical exposure, to allow aggressive lymphadenectomy around the upper mediastinum, and to allow thoracoscopic mobilization of the oesophagus. Therefore, OLV during oesophageal surgery has become a frequent method of choice.

During OLV, transient increases of $\mathrm{Q} / \mathrm{Q} / \mathrm{t}$ and decreases of $\mathrm{PaO}_{2}$ are well known but these changes returned immediately after OLV was stopped. ${ }^{2,10}$ This is confirmed by our results. Scherer ${ }^{1}$ and Sugihara ${ }^{2}$ reported that $\mathrm{CI}$ did not change during and immediately after OLV and the increase of MPAP and SVR during OLV were signs of hypoxic pulmonary vasoconstriction in the unventilated lung but these variables returned to the previous value after OLV was stopped: During OLV, hypoxia may be a severe problem. In this study, seven 

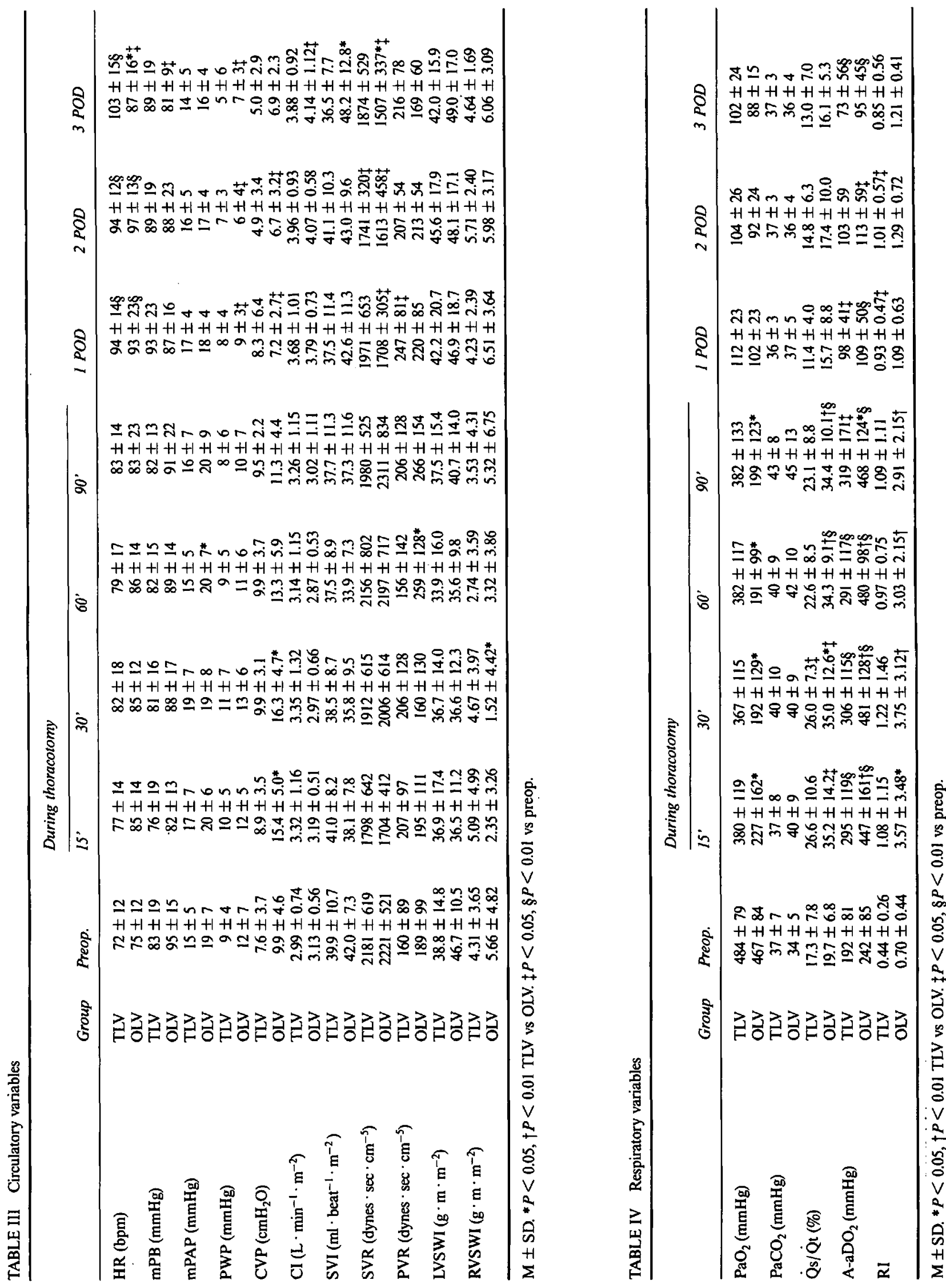


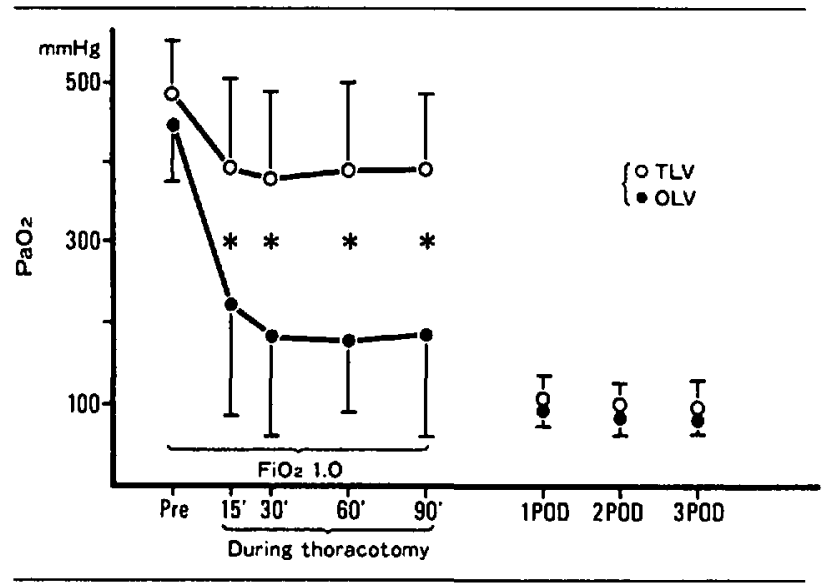

FIGURE 1 Changes of $\mathrm{PaO}_{2}$. Mean $\pm \mathrm{SD}{ }^{*} P<0.05 .{ }^{* *} P<0.01$.

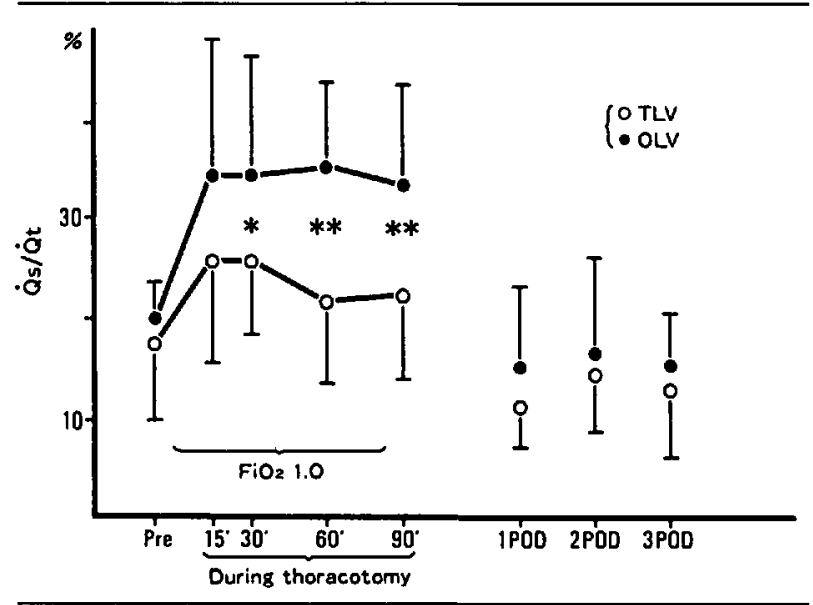

FIGURE 2 Changes of $\dot{\mathrm{Q}}_{\mathrm{s}} / \dot{\mathrm{Q}}_{\mathrm{t}}$ Mean $\pm \mathrm{SD} . * P<0.05 . * * P<0.01$.

of 15 patients in the OLV group had transient $\mathrm{PaO}_{2}$ values $<100 \mathrm{mmHg}$ within $30 \mathrm{~min}$ after OLV was started and one of the seven needed hyperinflation. Thus, careful observation of $\mathrm{PaO}_{2}$ is recommended within $30 \mathrm{~min}$ after the start of OLV."1

In the postoperative period, it has not been determined if the collapsed lung during OLV affects cardiopulmonary variables and pulmonary complications. Therefore, we prospectively evaluated the safety of OLV compared with two-lung ventilation (TLV) in a randomized fashion. First, cardiopulmonary variables were not different between the one-lung and two-lung ventilation (TLV) groups up to POD 3. Second, A-aDO ${ }_{2}$ increased in the postoperative period in both groups, but there was no difference between the two groups. Third, the rates of postoperative pulmonary complications and abnormal chest $x$-ray shadows were not different between the two groups. Sugihara ${ }^{2}$ reported that the rate of pulmonary complication after oesophagectomy using OLV was $12.5 \%$ and that was less than the $14.1 \%$ seen with non-OLV.
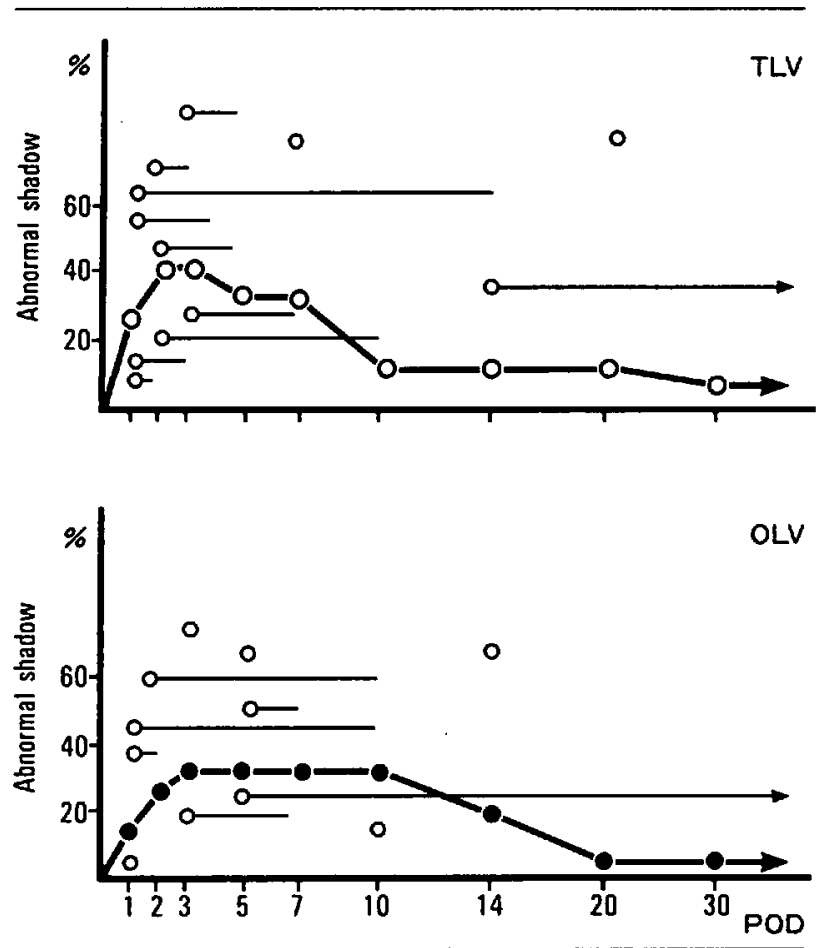

FIGURE 3 The frequency of abnormal chest $x$-ray findings. Each fine bar represents the duration of abnormal finding of each patient.

He considered that this was associated with decreased compression to the heart and lung by the surgical instruments and with decreased stimulation of the inspired gas to the bronchial mucosa of the non-ventilated lung during OLV. Imamura ${ }^{4}$ reported that during OLV in patients undergoing oesophagectomy for oesophageal cancer with pulmonary dysfunction, high-frequency jet ventilation contributed to a decrease of postoperative pulmonary complications and the survival curve of these patients was not different from that of other patients. For these reasons, it appears that OLV during oesophageal surgery does not affect postoperative cardiopulmonary changes and pulmonary complications compared with TLV.

Thus, it is concluded that OLV during oesophagectomy is as safe as TLV regarding the incidence of cardiopulmonary variables and pulmonary complications.

\section{References}

1 Scherer $R$, Van Aken $H$, Lawin $P$. Hämodyanmische und respiratorische Veränderungen bei Operationen am Oesophagus unter unilateraler Ventilation . Der Chirurg 1984; 55: 665-9.

2 Sugihara T, Makuuchi H, Sasaki T, Tajima T, Mitomi T, Yamazaki $Y$. One lung ventilation in thoracic esophageal operation: clinical experience using endotracheal tube with movable blocker. Japanese Journal of Gastroenterological Surgery 1985 ; 18: 1595-99. 
3 Nishi M, Yamanaka H, Hiramatsu Y, Hioki K, Yamamoto $M$, Mima $M$. Causes and countermeasures of respiratory failure after surgery for esophageal cancer. Japanese Journal of Gastroenterological Surgery 1987; 20: 2488-93.

4 Imamura $M$, Yanagibashi $K$, Tobe $T$, et al. Transthoracic resection of esophageal cancer in patients with pulmonary dysfunction: usefulness of high frequency ventilation during thoracotomy. Ann Surg 1988; 208: 601-5.

5 Carlens $E$. A new flexible double-lumen catheter for bronchospirometry. J Thorac Cardiovasc Surg 1949; 18: 742-7.

6 Peltola $K$. Central haemodynamics and oxygenation during thoracic anaesthesia. Acta Anaesthesiol Scand Suppl 1983; 27: 1-51.

7 Japanese Society of Esophageal Diseases. Guide Lines for the clinical and pathologic studies on carcinoma of the esophagus. Jpn J Surg 1976; 6: 69-78.

8 Benumof $J$. Physiology of the open chest and one-lung ventilation. In: J Kaplan (Ed.). Thoracic Anesthesia. London: Churchill Livingstone, 1983; 287-316.

9 McAnena OJ, Rogers $J$, Williams NS. Right thoracoscopically assisted oesophagectomy for cancer. Br J Surg 1994; 81: $236-8$.

10 Slinger $P$, Triolet $W$, Wilson J. Improving arterial oxygenation during one-lung ventilation. Anesthesiology 1988; 68: 291-5.

11 Malmkvist $G$. Maintenance of oxygenation during onelung ventilation: effect of intermittent reinflation of the collapsed lung with oxygen. Anesth Analg 1989; 68: 763-6. 